\title{
Profile of Clients of HIV Testing and Counseling in a Tertiary Care Center and Need of Testing in Tuberculosis
}

\author{
Shrestha $\mathbf{S}^{1}$, Karn $\mathbf{D}^{1}$, Tamrakar $\mathbf{D}^{2}$, Madhup $\mathbf{S}^{3}$, Karmacharya $\mathbf{B M}^{2}$ \\ ${ }^{1}$ Department of Dermatology; ${ }^{2}$ Department of Community Medicine; ${ }^{3}$ Department of Microbiology, Dhulikhel Hospital, \\ Kathmandu University
}

\begin{abstract}
Introduction: Sexually transmitted infection is public health issue that amplifies HIV burden globally. At National Center of AIDS and STD Control, annual reported STI are rising steeply recently. Incidence of HIV is $0.03 \%$ while prevalence in adult population is less than 1\%. National HIV testing guidelines 2017 recommends HIV tests should be performed in tuberculosis and medical conditions. However, it is not routinely done in Nepal.

Objective: To assess profile of STI and HIV among patients attending HIV testing and counseling center of tertiary hospital, and to assess fraction of tuberculosis patients undergoing HIV testing.

Materials and Methods: All patients attending HIV testing and counseling center were tested for HIV. Tests for STI were done based on patient symptoms. Data collected were analyzed with SPSS.

Results: Suspected STI (41.1\%) was commonest cause of HIV testing. Among STI, gram positive diplococcic were noted in $11.5 \%$ and $3.4 \%$ had PCR positive Chlamydia. Only $19.4 \%$ (7 out of 36) of total tuberculosis patients in hospital were screened for HIV, among which, $57.14 \%$ (4 out of 7) were seropositive for HIV, which is noteworthy.

Conclusion: Our study shows patterns of STI, and that gonorrhea and chlamydia could be underdiagnosed in Nepal. Every patient with tuberculosis should routinely be screened for HIV.But only small fraction of tuberculosis patients underwent HIV screening, out of which HIV positivity was high, reflecting the gap and need for routine HIV screening in TB patients.

Key words: Acquired Immunodeficiency Syndrome; HIV infections; Sexually Transmitted Diseases; Tuberculosis
\end{abstract}

\section{Introduction}

$\mathrm{H}_{\mathrm{s}}^{\mathrm{m}}$ $V$ testing and counseling (HTC) is entry point of HIV care services. ${ }^{1}$ It identifies important populations for targeting of HIV prevention efforts. In Nepal, HIV prevalence is decreasing since 2005. ${ }^{2,3}$ However, research on HIV heavily concentrates on high risk populations like sex workers, labor migrants, etc owing to concentrated epidemics among them. ${ }^{4,5}$ Population based or facility center based studies on HIVare minimal. STIs increase acquisition of Human immunodeficiency virus (HIV) and World Health Organization (WHO) STI estimates in 2012 showed highest prevalence of curable STI in South-East Asia. ${ }^{6}$ Globally, current trends show decline in syphilis and gonorrhea, with increase in chlamydia. ${ }^{7}$ There

\section{Address of Correspondence:}

Dr. Smriti Shrestha

Lecturer

Department of Dermatology

Dhulikhel Hospital Kathmandu University, Dhulikhel

E-mail: smiaaliyah@gmail.com is limited data on STI in Nepal due to lack of fully functional surveillance system. Previously, syphilis was commonest STI reported in Eastern Nepal while prevalence of gonorrhea and chlamydia were low. ${ }^{8,9}$ Our study is aimed at estimating the patterns of STI in Central Nepal.

Submitted: $28^{\text {th }}$ October 2018

Accepted: $30^{\text {th }}$ January 2019

Published: $31^{\text {st }}$ March 2019

How to cite this article

Shrestha S, Karn D, Tamrakar D, Madhup S, Karmacharya BM. Profile of clients of HIV testing and counseling in a tertiary care center and need of testing in tuberculosis. Nepal Journal of Dermatology Venereology and Leprology. 2019;17(1):22-6. doi: http://dx.doi. org/10.3126/njdvl.v17i1.23251

\section{(c) (i)}

Licensed under CC BY 4.0 International License which permits use, distribution and reproduction in any medium, provided the original work is properly cited. 


\section{Materials and Methods}

$\mathrm{T}_{\mathrm{b}}^{\mathrm{s}}$ his is a cross-sectional observational hospitalbased study conducted in HIV testing and counseling clinic in Dermatology Department. All patients attending HTC clinic from December 2016 to November 2017 were enrolled; following approval from Institutional Review Board of Kathmandu University School of Medical Sciences.An informed consent was taken. Demographic characteristics such as age, gender, occupation, use of condom, high risk behavior and clinical symptoms of genital ulcer, discharge and genital lesions were noted. Patients of all ages presenting to HTC clinic were included. HIV I \& II reactivity was tested in all patients with HIV Tridot rapid test kit. Positive results were further confirmed by HIV ELISA tests (ACCU Diag. Diagnostic Automations. USA). Tests for various STI were done based on clinical symptoms. In men with urethral discharge, samples for gram stain and pus culture were collected under direct guidance of the principal investigator, in order to prevent false negative results due to inappropriate sample collection technique. In all cases with urethral discharge, early morning first void urine sample were collected for Chlamydia PCR, performed by microbiologist at our center. The principal investigator completed the case proforma containing clinical, demographic characteristics and investigations done in each patient. Data was entered in Microsoft excel and analysed by SPSS. Descriptive data will be provided in tables and figures.

\section{Results}

In this study, among 280 candidates undergoing HTC, majority (84.6\%) were in the age group between 20-49 years. (Table 1) Mean age of $31.20+/-0.62$ years. Among them, $81.4 \%$ were male and only $18.6 \%$ were female, with male to female ratio of $4.3: 1.0 n l y$ $5(0.17 \%)$ patients were positive for HIV, of which 3 were men and 2 were women (M:F=1.5:1).

Table 1: Age of the patients attending HTC center.

\begin{tabular}{|c|c|c|}
\hline Age & Number & Percentage \\
\hline less than 20 & 21 & 7.5 \\
\hline $20-30$ & 108 & 38.6 \\
\hline $30-40$ & 83 & 29.6 \\
\hline $40-50$ & 46 & 16.4 \\
\hline $50-60$ & 19 & 6.8 \\
\hline $60+$ & 3 & 1.1 \\
\hline Total & $\mathbf{2 8 0}$ & $\mathbf{1 0 0 . 0}$ \\
\hline
\end{tabular}

Occupation of the clients were labor migrants 116 (41.5\%), drivers 67 (23.9\%), laborers 33 (11.8\%), salesmen $8(2.8 \%)$, immigrants from India $12(4.3 \%)$, housewife 34 (12.1\%) and Others 10 (3.6\%).Condom use was found in 97 (34.6\%) cases, among which only $42(15 \%)$ patients were using it regularly during each sexual contact. Hormonal contraception was noted in 32 (22.4\%) cases and as high as 150 (53.6\%) cases gave no history of any contraception.

The most common reason for testing was suspected STI seen in 115 (41.1\%) patients, followed by skin diseases in 98 (35\%), prolonged fever in 14 (5\%), other medical causes in 17 (6.1\%), patient initiated or demanded in $21(7.5 \%)$, IV drug abuse in 8 (2.9\%) and tuberculosis in $7(2.5 \%)$ patients respectively (Figure 1$)$.

Among patients with suspected STI, 87 (75.65\%) had some form of sexually transmitted infections, 23 (20\%) had venerophobia and 5 (4.35\%) had history of STI in partner.

Commonest STI was genital verruca (Table 2). Among male patients with urethral discharge, gram stain showed gram negative intracellular diplococci in 10 patients (11.5\%), out of which culture was positive in only four patients. Chlamydia PCR was sent in all cases of suspected gonorrhea, out of which, only 3 (3.4\%) were positive for Chlamydia.

Table 2: Sexually transmitted infections undergoing HTC

\begin{tabular}{|l|c|}
\hline Diagnosed STI & Number (Percentage\%) \\
\hline Genital verruca & $29(33.3 \%)$, \\
\hline Genital discharge & $19(21.8 \%)$ \\
\hline Genital ulcer & $13(14.9 \%)$ \\
\hline Orogenital candidiasis & $14(16.1 \%)$, \\
\hline Genital molluscum & $8(9.1 \%)$ \\
\hline Syphilis & $4(4.6 \%)$ \\
\hline Total & $\mathbf{8 7}(\mathbf{1 0 0 \% )}$ \\
\hline
\end{tabular}

Among total patients tested for HIV, only 5(1.78\%) were reactive for HIV. Among seropositive cases, 4 out of 5 seropositive cases were of tuberculosis. (Figure 2).

It is important to note that cases of TB tested for HIV was low compared to total TB cases in the hospital. There were 36 cases of diagnosed TB in our hospital this year, but only seven (19.44\%) TB patients were referred for HIV testing (Figure 3 ). 


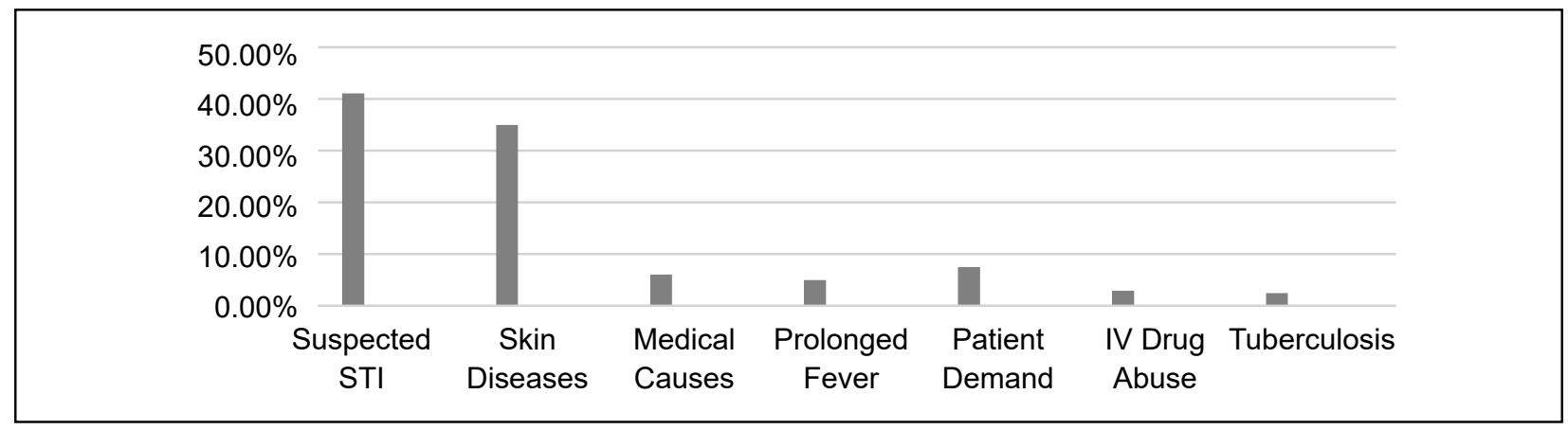

Figure 1: Reasons for HIV testing and counseling.

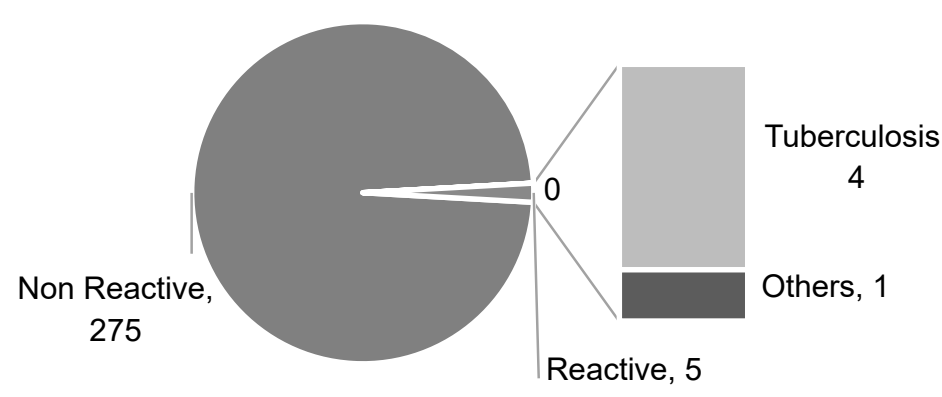

Figure 2: HIV test results of total patients.

\section{Discussion}

HIV counseling and testing is the first step in detecting and managing HIV. Adult prevalence of HIV in less than $1 \%$ and incidence is $0.05 \%$ worldwide. ${ }^{10}$ In Nepal, prevalence of HIV is low, affecting $0.17 \%$ adults (15-49 years) by December $2016 .^{3}$

HIV counseling and testing is one of the key strategies that decreased the burden of HIV. ${ }^{3,10}$ There were 175 HTC centers in Nepal that provide free of cost services to general population. ${ }^{11}$ HTC identifies important populations for targeting HIV prevention efforts. High risk groups include intravenous drug abuse (IVDA), female sex worker (FSW), labor migrants (LM), men who have sex with men and transgender (MSMTG) community. The prevalence of HIV is over 5-fold more in high risk population compared to general populations and they are 13-14 times more at risk to contract HIV. ${ }^{12}$ National Center for AIDS and STD Control (NCASC) and IBBS (Integrated Biological and Behavioral Survey) in Nepal showed that majority of STI and HIV is concentrated among high risk groups and many studies are based on these high risk groups. ${ }^{4,5,9}$

In our study, $1.7 \%$ of tested subjects were positive for HIV. NCASC reported $1.2 \%$ HIV positives among tested and highest burden (1.6\%) was observed in central Nepal, similar to our study. ${ }^{11}$
Majority of our HTC clients were between 20-49 years of age. In Nepal, $48 \%$ of the total population falls in this vulnerable age group of 15-49 years, and our national data is consistent with our report. ${ }^{2,11}$ Ratio of male to female was $4.3: 1$ in this study. Higher ratio of male patients could because of few reasons such as high risk behavior among men such as multiple partners, outdoor profession such as driving and labor migrants and hesitation among females to attend medical centers.But the gender ratio among HIV positive patients was1.5:1, close to national survey of 2:1 ratio. ${ }^{13}$ This discrepancy among men attending HTC clinics versus HIV positive men, is perhaps because of above mentioned reasons.

National HIV testing and treatment guidelines 2017 states that reason for testing in facility can be provider initiated or client initiated. ${ }^{3}$ In this study, various reasons for testing included provider initiated and client initiated tests. Commonest reason for testing was STI (41.1\%), among which genital verruca was the most common diagnosis, consistent with previous study at our center. ${ }^{14}$ However, Garg et all reported syphilis as commonest STI in Eastern Nepal. ${ }^{8}$ In current study, gram positive gonococcal infection was seen in $11.5 \%$ of STI and $3.4 \%$ had chlamydia.Prevalence of gonorrhea is higher in our study compared to previous report of $1.0 \%$ in population based study in rural Nepal, but results of chlamydia is comparable (2.3\%). However, current trends in South-East Asia and 
globally shows decline in syphilis and gonorrhea, with increase in Chlamydia. ${ }^{6,7}$

Majority of clients were labor migrants, drivers and laborers, similar to previous studies. ${ }^{8,14}$ We did not have high risk people such as FSW and IVDA in our study, which perhaps reflects the gap in accessibility of HTC services among high risk population. Previous study done in three districts of Nepal showed that $54 \%$ of FSW and $45 \%$ of MSM/TG did not utilize HTC services. ${ }^{15}$ Another study in 22 Terai districts, showed substantial decline in FSW visiting HTC services in 2017 compared to $2012 .{ }^{16}$ This is worrisome. National HIV testing guideline emphasizes the importance of community based testing in high risk population. ${ }^{3}$ But the gap between guidelines and results call for targeted interventions to address risk behaviors, awareness and attitude towards HIV and psychosocial impact of HIV testing in high risk population urgently.

Likewise, tuberculosis is established as high risk factor for acquiring HIV. HIV and TB is a deadly "syndemic". ${ }^{17}$ Tuberculosis patients are 19 times more likely to be infected with HIV than those without TB, and HIV patients are 26 times more likely to develop TB than healthy individuals. ${ }^{18}$ Among 33.4 million people living with HIV in 2008, nearly $30 \%$ were estimated to have latent or active TB infection and tuberculosis is the leading cause of death among HIV patients. Globally in 2014, 51\% of TB patients (3.2 million) had a documented HIV test. ${ }^{17,18}$ Our National HIV Testing Guidelines of Nepal clearly states the need for HIV screening in all TB patients. ${ }^{3}$ However, in our study, only small fraction of clients referred for HTC had TB (2.5\%). Actual TB patients attending our tertiary care center is much higher. This is just a tip of an iceberb. But despite very low referrals, $80 \%$ of HIV positive patients (4/5) in our study were known case of tuberculosis. This finding is striking but might not reflect actual burden due to low number of referral cases of TB. In Eastern

\section{References}

1. Urmi AZ, Leung DT, Wilkinson V, Miah MA, Rahman M, Azim T. Profile of an HIV Testing and Counseling Unit in Bangladesh: Majority of New Diagnoses among Returning Migrant Workers and Spouses. PLoS One. 2015;10(10):e0141483 https://doi.org/10.1371/journal.pone.0141483

2. Paudel $T$, Singh $N$, Raj Banjara $M$, et al. Epidemiology of HIV, programmatic progress and
India, differing from our study, $12.3 \%$ of tuberculosis patients were HIV positive. ${ }^{19}$

This prompted us to analyze discrepancy between recommendations and actual fraction of TB patients receiving HTC in Nepal. Incidence of TB is increasing in recent years and more than $90 \%$ of global TB cases and deaths occur in developing world. ${ }^{20}$ Another study describes caseload of tuberculosis in South-East Asiaas "staggering". ${ }^{21}$ In this scenario, it is dubious that the syndemic is reported in only $3.5 \%$ in South-East Asia while TB/HIV co-infection is $12.5 \%$ globally. This raises a pertinent question regarding total case burden of this syndemic. In 2015 , almost $60 \%$ of TB cases among HIV patients were not diagnosed according to $\mathrm{WHO} \cdot{ }^{18} \mathrm{Amid}$ this huge gap, WHO has set ambitious target of 90-90$90 "$ by 2020 , i.e. $90 \%$ HIV patients know their serostatus by 2020 . We would like to put forward that one of the measures needed to achieve this ambitious target is to routinely screen all tuberculosis patients for HIV.

Our study is conducted in a tertiary care center. Itmight not reflect burden in the community. Moreover, asymptomaticc carriers who do not seek medical care were missed.

\section{Conclusion}

It is essential to measure the regional prevalenceof STI in Nepal to be able to estimate impact sexual health and HIV. Gonorrhea and chlamydia are underdiagnosed in Nepal. This calls for better laboratory facilities across Nepal, to prevent complications and resistance of these disease with huge global burden. The take home message of this study is that every patient with TB should routinely be screened for HIV, in accordance with National HIV testing guidelines.

Financial disclosure: None.

Conflict of interest to disclosure: None declared. gaps in last 10 years in Nepal. Journal of Virus Eradication. 2016;2(Suppl 4):35-40.

3. National HIV Testing and Treatment Guidelines 2017. NCASC. Available from: http://www.searo. who.int/nepal/documents/communicable diseases/national_hiv_testing_and_treatment_ guidelines_2017_(23june2017).pdf (accessed on September 2018). 
4. Kakchapati S, Gautam N, KC KP, Rawal BB. HIV awareness and safe sexual behaviors among female sex workers in Kathmandu valley of Nepal. HIV/AIDS (Auckland, NZ). 2018;10:157166. https://doi.org/doi:10.2147/HIV.S163269

5. National Center for AIDS and STD Control Integrated biological and behavioral surveillance survey (IBBS) 2017. Available from: http://www. aidsdatahub.org/nepal-2017-factsheet-ibbssurveys-national-center-aids-and-std-controlncasc-2017.

6. Newman L, Rowley J, Vander HS, Wijesooriya NS, Unemo M, Low Net al. Global Estimates of the Prevalence and Incidence of Four Curable Sexually Transmitted Infections in 2012 Based on Systematic Review and Global Reporting. Meng Z, ed. PLoS ONE. 2015;10(12):e0143304. https:// doi.org/10.1371/journal.pone.0143304

7. Chan R. Sexually transmitted infections in Asia and the Pacific-an epidemiological snapshot. Sexually Transmitted Infections. 2011;87(Suppl 2):ii14-ii15. https://doi. org/10.1136/sti.2010.047597.

8. Gark VK, Agarwalla A, Agrawal S, Deb M, Khanal B. Sexual habits and clinico-etiological profile of sexually transmitted diseases in Nepal. J Dermatol 2001. Jul;28(7):353-9.

9. Christian $\mathrm{P}$, Khatry SK, LeClerq SC; A A Roess; L Wu; J D Yuenger; J M Zenilman. Prevalence and risk factors of chlamydia and gonorrhea among rural Nepali women. Sexually Transmitted Infections. 81(3):254258, JUN 2005. https://doi.org/10.1136/ sti.2004.011817

10. Fettig J, Swaminathan M, Murrill CS, Kaplan JE. Global Epidemiology of HIV. Infectious disease clinics of North America. 2014;28(3):323-337. https://doi.org/10.1016/j.idc.2014.05.001

11. National Center for AIDS and STD Control. Factsheet 3: HIV Testing and Counselling Services, as of July 2017. Available from: http:// www.ncasc.gov.np/WAD2017/ (accessed on 19 $9^{\text {th }}$ September 2018).

12. World Health Organization, United Nations Children's Fund, The Joint United Nations Programme on HIV and AIDS. 2013. Global update on HIV treatment 2013: results impact and opportunities. Geneva: WHO, UNICEF,
UNAIDS. Available from: http://www.unaids. org/en/resources/documents/2013/20130630_ treatment_report. [accessed on 21st September 2018].

13. National Center for AIDS and STD Control. Factsheet 1: HIV epidemic update of Nepal, as of Dec 2016. Available from http://www.ncasc. gov.np/WAD2017/FACTSHEET-2017-FINAL/ Factsheet-1-HIV-epidemic-update-2017.pdf (accessed on $22^{\text {nd }}$ September 2018)

14. Karn D, Amatya A, Aryal ER, KC S, Timalsina M. Prevalence of sexually transmitted infections in a tertiary care center. Kathmandu Univ Med J 2011. Apr-Jun;9(34):44-8.

15. Shrestha R, Philip S, Shewade HD, Rawal B, Deuba K. Why don't key populations access HIV testing and counselling centres in Nepal? Findings based on national surveillance survey. BMJ Open. 2017;7(12):e017408. doi:10.1136/ bmjopen-2017-017408. https://doi.org/10.1136/ bmjopen-2017-017408

16. National Center for AIDS and STD Control Integrated Biological and Behavioral Surveillance (IBBS) Survey among Female Sex Workers in Kathmandu Valley Round VI, 2017 Available at: http://www.aidsdatahub.org/sites/default/ files/publication/Nepal_IBBS_Factsheet_IBBS_ FSWs_2017.pdf (accessed 22 ${ }^{\text {nd }}$ September 2018)

17. Kwan CK, Ernst JD. HIV and tuberculosis: a deadly human syndemic. Clin Microbiol Rev. 2011 Apr;24(2):351-76. https://doi.org/10.1128/ CMR.00042-10

18. TB/HIV Facts 2015. World Health Organization. Available at : http://www.who.int/hiv/topics/ tb/tbhiv_facts_2015/en/ (accessed on 22 ${ }^{\text {nd }}$ September 2018)

19. Manjareeka M, Nanda S. Prevalence of HIV infection among tuberculosis patients in Eastern India. Journal of Infection and Public Health. 2013 Oct;6(5),p358-362. https://doi.org/10.1016/j.jiph.2013.04.004

20. Chadha VK. Progress towards millennium development goals for TB control in seven Asian countries.Indian J Tuberc. 2009 Jan; 56(1):30-43.

21. Basnyat B, Caws M, Udwadia Z. Tuberculosis in South Asia: a tide in the affairs of men. Multidisciplinary Respiratory Medicine. 2018;13:10. doi:10.1186/s40248-018-0122-y. https://doi.org/10.1186/s40248-018-0122-y 